Proceedings

\title{
Extraction of Iron from Russian Red Mud by a Carbothermic Reduction and Magnetic Separation Process ${ }^{\dagger}$
}

\author{
Dmitry Zinoveev ${ }^{1,}{ }^{*}$, Alexander Petelin ${ }^{2}$, Pavel Grudinsky ${ }^{1}$, Andrey Zakunov ${ }^{1,2}$ and Valery Dyubanov ${ }^{1}$
}

Citation: Zinoveev, D.; Petelin, A.; Grudinsky, P.; Zakunov, A.; Dyubanov, V. Extraction of Iron from Russian Red Mud by a Carbothermic Reduction and Magnetic Separation Process. 2021, 3, x. https://doi.org/10.3390/xxxxx

Published: 22 February 2021

Publisher's Note: MDPI stays neutral with regard to jurisdictional claims in published maps and institutional affiliations.

Copyright: (C) 2021 by the authors. Submitted for possible open access publication under the terms and conditions of the Creative Commons Attribution (CC BY) license (http://creativecommons.org/licenses /by/4.0/).
1 Laboratory of Physical Chemistry and Technology of Iron Ore Processing, A.A. Baikov Institute of Metallurgy and Materials Science, Russian Academy of Science, 49 Leninsky prosp, Moscow 119334, Russia; dzinoveev@imet.ac.ru (D.Z.), pgrudinskiy@imet.ac.ru (P.G.), vdyubanov@imet.ac.ru (V.D.), az437@yandex.ru (A.Z.)

2 Department of Energy-Efficient and Resource-Saving Industrial Technologies, National University of Science \& Technology (MISIS), 4 Leninsky prosp., Moscow 119049, Russia; sasha@misis.ru (A.P.)

* Correspondence: dzinoveev@imet.ac.ru; Tel.: +7-499-135-94-49

+ Presented at the 1st International Electronic Conference on Metallurgy and Metals, online, 22 February -07 March 2021.

\begin{abstract}
Red mud is a hazardous waste of alumina production. Currently, the total accumulated amount of red mud is over 4 billion tons. The promising method of red mud processing is carbothermic reduction of iron at $1000-1400{ }^{\circ} \mathrm{C}$ into metallic form followed by magnetic separation. In this study, the mechanism of carbothermic solid-phase reduction of red mud was investigated. Based on the experimental data, the two-step mechanism of the first rapid stage of the process was proposed, which leads to almost full iron reduction. The estimated value of activation energy has indicated that solid-phase diffusion is a rate-controlling step for this stage. However, almost full reduction is necessary, but insufficient factor for successful magnetic separation. The second crucial factor of the process is enlargement of iron grain size, which leads to gangue-grain release during grinding and increases efficiency of the magnetic separation. The prediction model of iron grain growth process during the carbothermic reduction process was suggested. The calculation of average size of iron grains formed during reduction process that performed according to the assumption of diffusion-controlled process showed their correlation with experimental data. Various methods were proposed to promote the process of iron grain growth during carbothermic reduction of red mud.
\end{abstract}

Keywords: red mud; carbothermic reduction; magnetic separation, solid-phase reduction, iron grain growth, reduction

\section{Introduction}

Red mud is a waste of alumina production from the bauxite ore. The obtaining of 1 ton of alumina generates $0.8-1.5$ tons of red mud [1]. Recycling or utilization of red mud is an important current task due to both environmental and economic reasons. Firstly, red mud occupies large areas and causes an adverse environmental impact [2]. Secondly, red mud is a valuable material for extractive metallurgy owing to significant contents of iron, aluminum, titanium, and rare-earth metals [3]. The typical content of $\mathrm{Fe}_{2} \mathrm{O}_{3}$ in red mud is in the range of 30-60\% [4] that enables to consider its treatment to extract iron.

The promising way for iron recovery from red mud is its reduction into metallic form [5]. An implementation of this approach requires a creation of physicochemical conditions for iron reduction and a development of a technological process for the treatment of significant amounts of red mud. The common reduction process is carbothermic roasting at the range of $1000-1400{ }^{\circ} \mathrm{C}$ followed by magnetic separation. This method allows to use a cheap carbon-containing material as a reducing agent and carry 
out the treatment in air without the formation of melts. To obtain iron metallic concentrate, grinding and magnetic separation of the reduced material is needed. The crucial factor of the efficiency of magnetic separation is sufficient iron grain size to release gangue from the metallic part during grinding. Therefore, the physicochemical conditions of the metallization process should provide not only full reduction of iron oxides, but also a certain size of metallic particles above a certain limit.

This study focuses on a mechanism of the carbothermic solid-phase reduction of iron in red mud, as well as prediction model of iron grain growth process. Kinetic parameters of the reduction process were estimated and the decisions were proposed to promote the process of iron grain growth during carbothermic reduction.

\section{Materials and Methods}

Ural Aluminum Plant (Russia) provides a red mud sample, which was treated by lime milk at $90{ }^{\circ} \mathrm{C}$ for $180 \mathrm{~min}$ to lixiviate sodium. The sample has the chemical composition as follows: $25.8 \% \mathrm{Fe}, 17 \% \mathrm{Ca}, 6.3 \% \mathrm{Al}, 4.1 \% \mathrm{Si}, 2.1 \% \mathrm{Ti}, 0.6 \% \mathrm{Mg}, 0.4 \% \mathrm{P}, 0.2 \% \mathrm{Na}, 0.1 \% \mathrm{~S}$. The main iron-containing phase of the red mud sample was $\alpha-\mathrm{Fe}_{2} \mathrm{O}_{3}$ (hematite). Experimental carbothermic reduction was carried out the same as in our previous studies [6,7]. Red mud was pressed in tablets and placed into the crucible filled with a considerable excess of finely ground coal to reduce iron; the reduction was carried out in the muffle furnace in the range of $1000-1200^{\circ} \mathrm{C}$.

\section{Results}

Figure 1 gives the kinetic dependence of iron metallization degree at various temperatures.

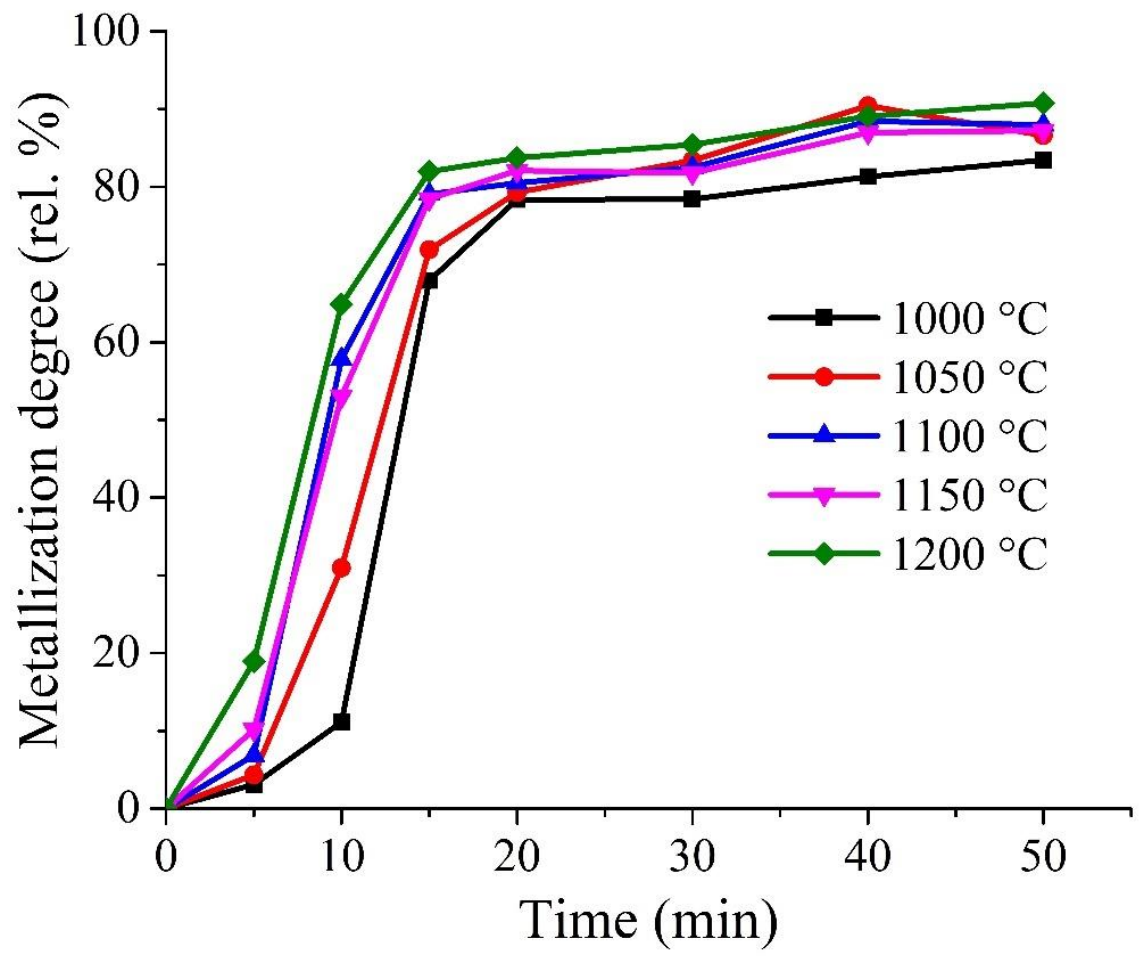

Figure 1. Effect of temperature and reduction time on iron metallization degree.

As can be seen, the process consists of two sectors including sharp increasing of metallization rate up to 15-20 min and then its moderating growth. The maximum degrees of metallization at all the temperatures are no more than $80-90 \%$, although the thermodynamic potential of the reducing agent is sufficient for full reduction because of 
its excess. Hence, the incomplete reduction is probably due to a kinetic mechanism of the process.

In any case, the rate of the first stage of the process depends on the surface area of iron oxides available for the interaction with the reducing agent. It is clear that the contact of oxide-carbon surfaces in the powder mixture of red mud and solid carbon can be mostly pointwise, especially at the initial stage of the process, while diffusion sintering of the powder particles is not essential. Therefore, there is a point reduction of iron oxides in the first moments of the treatment with a generation of gaseous carbon oxides. Obviously, the carbothermic reduction of iron oxides occurs after an appearance of carbon oxides according the following reactions:

$$
\begin{gathered}
3 \mathrm{Fe}_{2} \mathrm{O}_{3(\mathrm{~s})}+\mathrm{CO}_{(\mathrm{g})}=2 \mathrm{Fe}_{3} \mathrm{O}_{4(\mathrm{~s})}+\mathrm{CO}_{2(\mathrm{~g}),} \\
\mathrm{Fe}_{3} \mathrm{O}_{4(\mathrm{~s})}+\mathrm{CO}_{(\mathrm{g})}=3 \mathrm{FeO}_{(\mathrm{s})}+\mathrm{CO}_{2(\mathrm{~g})} \\
\mathrm{FeO}_{(\mathrm{s})}+\mathrm{CO}(\mathrm{g})=\mathrm{Fe}_{(\mathrm{s})}+\mathrm{CO}_{2(\mathrm{~g})} \\
\mathrm{CO}_{2(\mathrm{~g})}+\mathrm{C}_{(\mathrm{s})}=2 \mathrm{CO}(\mathrm{g}) .
\end{gathered}
$$

Evidently, the reactions (1) and (2) goes rapidly, so the total reaction can be written as a sum of the reactions (3) and (4):

$$
\mathrm{FeO}_{(\mathrm{s})}+\mathrm{C}_{(\mathrm{s})}=\mathrm{Fe}_{(\mathrm{s})}+\mathrm{CO}_{(\mathrm{g})} .
$$

In our case, assuming the gas diffusion is not a rate-controlling step, and the autocatalytic reaction (4) also occurs rather quickly at the temperatures of the experiments, the reduction degree at this stage can be limited by a surface area of the iron oxides available for gas reduction in the red mud samples. To increase the rate of the initial stage of the metallization process, an increase in the outer surface of the iron oxides is needed that can be achieved by an additional grinding of red mud.

The second stage of the overall process begins after the sintering process occludes the through pores for a free penetration of carbon-containing gases. Therefore, $\mathrm{CO}_{2}$ can't leave the $\mathrm{FeO}$ surface fast enough to provide $\mathrm{CO}$ an area for the interaction with the oxide, so the reduction process proceeds slowly. The reduction degree increases due to the growth of already formed small iron grains from the surface toward the interior of solid phases. The reducing agent can penetrate through the solid layers as not molecules, but as atoms, so two additional steps can be distinguished during the reduction process, namely, a dissociation of $\mathrm{CO}$ or $\mathrm{CO}_{2}$ molecules to atoms and diffusion of the atoms into the crystal lattice of solid oxides. The diffusion step includes a supply of the reducing agent to the interphase boundary of $\mathrm{FeO}-\mathrm{Fe}$ and a removal of excessive oxygen atoms from this boundary. The value of apparent activation energy ( $\left.E_{A}\right)$ determines a rate-controlling step.

Based on the Arrhenius equation, EA was calculated according to the data from Figure 1. The EA value is in the range of $200-215 \mathrm{~kJ} / \mathrm{mol}$ within the time interval of $0-10$ $\mathrm{min}$, while it is in the range of $5-10 \mathrm{~kJ} / \mathrm{mol}$ at $10-20 \mathrm{~min}$. The EA value of $200-215 \mathrm{~kJ} / \mathrm{mol}$ is approximate to the EA value of diffusion of oxygen atoms in metal oxides [8]. It can be assumed that the reduction process at this interval is limited by the migration of atoms in the crystal lattice of FeO. The EA value of further process considerably decreases, so the diffusion is not a rate-controlling step at $10-20 \mathrm{~min}$.

Taking into account diffusion control of the reduction rate at the stage of the rapid increasing of the degree of metallization, it is possible to estimate the average size of metallic iron grains using Wagner's theory [9], which allows to calculate the migration rate of the interphase $\mathrm{FeO}-\mathrm{Fe}$ boundary at any time according to the diffusion characteristics of the system. The distance $\chi$ covered by the interphase boundary in a time $t$ can be evaluated as follows:

$$
\chi=\sqrt{2 \cdot D_{0 x} \cdot t \cdot \frac{C_{5}-C_{1}}{C_{1}-C_{2}^{\prime}}}
$$


where $C_{S}$ is oxygen concentration in $\mathrm{FeO}\left(\approx 0.53\right.$ at. \%); $C_{1}$ is oxygen concentration in the solid solution of $\mathrm{FeO}$ in a range of its homogeneity ( $\approx 0.05$ at. \%); $C_{2}$ is oxygen concentration in the solid solution of Fe $\left(\approx 0.01\right.$ at. \%); $D_{o x}$ - oxygen diffusion coefficient in solid $\mathrm{FeO}, \mathrm{m}^{2} / \mathrm{s}$. It can be accepted that if the iron grains are spheroidal, the covered distance is equal to radius: $\chi \approx r$. According to [8], we accept $D_{o x}=6.2 \cdot 10^{-8} \cdot \exp (-240000 / \mathrm{RT})$.

Table 1 demonstrates the results of the calculation according to the equation (6).

Table 1. The calculation of iron grain size according to the Wagner theory.

\begin{tabular}{ccc}
\hline Temperature, ${ }^{\circ} \mathbf{C}$ & $\boldsymbol{D}_{\boldsymbol{o x}}, \mathrm{m}^{2} / \mathbf{s}$ & $\mathbf{r}, \boldsymbol{\mu m}$ \\
\hline 1000 & $8.7 \cdot 10^{-18}$ & 0.5 \\
1100 & $4.5 \cdot 10^{-17}$ & 1.1 \\
1200 & $1.7 \cdot 10^{-16}$ & 2.2 \\
\hline
\end{tabular}

The calculated sizes of iron grains are consistent with the experimental data obtained in $[6,7]$.

\section{Discussion}

The analysis of carbothermic solid-phase reduction of red mud has enabled to consider the stages that influence the degree of metallization of the total process. We assume that kinetic mechanisms are similar at all experimental temperatures in the range of $1000-1200^{\circ} \mathrm{C}$. The obtained data indicate that the carbothermic solid-phase process led to a high degree of iron metallization, but the crucial task is an enlargement of size of reduced iron grains up to the required value for the subsequent magnetic separation. Based on the results of the study, we recommend the following decisions:

- Increasing the fineness of red mud the for reduction process at $1000-1200{ }^{\circ} \mathrm{C}$ with a simultaneous increment of the treatment time to decrease the sintering rate that can lead to a promotion of gas reduction stage and an increase of iron growth rate on the surface;

- A rise the reduction temperature above $1200{ }^{\circ} \mathrm{C}$ or an addition to red mud of materials with low melting point to lower the temperature of the molten phase formation that can lead to the growth of reduced iron particles due to an additional effect of liquid diffusion.

Author Contributions: Conceptualization, A.P.; methodology, D.Z. and P.G.; investigation, D.Z., P.G., and A.Z.; resources, A.P. and V.D.; writing-original draft preparation, A.P. and P.G.; writing-review and editing, D.Z.; visualization, P.G.; supervision, A.P. and V.G..; project administration, A.P.; funding acquisition, A.P. All authors have read and agreed to the published version of the manuscript.

Funding: The present study was funded by RFBR according to Research Project No. 18-29-24186.

Acknowledgments: In this section, you can acknowledge any support given which is not covered by the author contribution or funding sections. This may include administrative and technical support, or donations in kind (e.g., materials used for experiments).

Conflicts of Interest: The authors declare no conflict of interest.

\section{References}

1. Liu, X.; Zhang, N. Utilization of red mud in cement production: A review. Waste Manag. Res. 2011, 29, 1053-1063. DOI: 10.1177/0734242X11407653.

2. Mayes, W.M.; Burke, I.T.; Gomes, H.I.; Anton, D.; Molnár, M.; Feigl, V.; Ujaczki Advances in Understanding Environmental Risks of Red Mud After the Ajka Spill, Hungary. J. Sustain. Metall. 2016, 2, 332-343. DOI: 10.1007/s40831-016-0050-z.

3. Bonomi, C.; Cardenia, C.; Yin, P.T.W.; Panias, D. Review of technologies in the recovery of iron, aluminium, titanium and rare earth elements from bauxite residue (Red Mud). In Proceedings of the 3rd International Symposium on Enhanced Landfill Mining, Lisbon, Portugal, 8-10 February 2016; pp. 259-276. 
4. Rai, S.; Wasewar, K.L.; Mukhopadhyay, J.; Yoo, C.K.; Uslu, H. Neutralization and utilization of red mud for its better waste management. Arch. Environ. Sci. 2012, 6, 13-33.

5. Keskinkilic, E.; Pournaderi, S.; Geveci, A.; Topkaya, Y.A. Solid-State Reduction Studies for Recovery of Iron from Red Mud. In Proceedings of the 11th International Symposium on High-Temperature Metallurgical Processing; Peng, Z., Ed.; Springer: Cham, Switzerland, 2020; pp. 511-519.; DOI: 10.1007/978-3-030-36540-0_45.

6. Zinoveev, D.; Grudinsky, P.; Zakunov, A.; Semenov, A.; Panova, M.; Valeev, D.; Kondratiev, A.; Dyubanov, V.; Petelin, A. Influence of $\mathrm{Na}_{2} \mathrm{CO}_{3}$ and $\mathrm{K}_{2} \mathrm{CO}_{3}$ addition on iron grain growth during carbothermic reduction of red mud. Metals 2019, 9, 1313. DOI: $10.3390 /$ met9121313.

7. Grudinsky, P.; Zinoveev, D.; Pankratov, D.; Semenov, A.; Panova, M.; Kondratiev, A.; Zakunov, A.; Dyubanov, V.; Petelin, A. Influence of Sodium Sulfate Addition on Iron Grain Growth during Carbothermic Roasting of Red Mud Samples with Different Basicity. Metals 2020, 10, 1571. DOI: 10.3390/met10121571.

8. Smithells, C.J. Metals reference book; 5th ed.; Butterworth: London, UK, 1976; 1566 p.

9. Bokstein, B.S. Diffusion in metals; Metallurgiya: Moscow, Russia, 1978; 248 p. (in Russian) 